\title{
Model selection and stress prediction of Ti-45Al-9Nb alloy during hot deformation
}

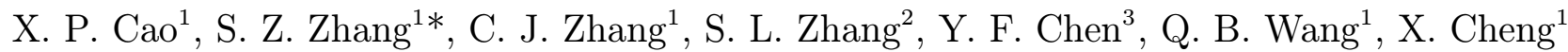 \\ ${ }^{1}$ School of Materials Science and Engineering, Taiyuan University of Technology, Taiyuan 030024, P. R. China \\ ${ }^{2}$ School of Mechanical Engineering, Ningxia University, Ningxia 750021, P. R. China \\ ${ }^{3}$ Ningbo Branch of China Ordnance Academy, Ningbo 315000, P. R. China
}

Received 19 April 2019, received in revised form 12 September 2019, accepted 10 October 2019

\begin{abstract}
Hot compression tests of as-cast Ti-45Al-9Nb alloy (in at.\%) were conducted in the temperature range of 1473 to $1548 \mathrm{~K}$ and at the strain rates of 0.01 to $0.1 \mathrm{~s}^{-1}$. The deformation activation energy $Q$ was determined as $524.89 \mathrm{~kJ} \mathrm{~mol}^{-1}$ by the Hyperbolic-sine constitutive equation. To select a preferable model to describe the relationship between stress and strain, both the dynamic softening model and the modified Arrhenius constitutive model have been developed to predict the stress-strain curves of the high $\mathrm{Nb}$ containing TiAl based alloy during hot deformation. Due to the constant material parameter of $c$, the flow stress predicted by the dynamic softening model had a large error with the measured stress.

Moreover, the deviation between the predicted and experimental data increased with the increase in strain rate and the decrease in temperature. When the material constant is expressed as the polynomial function of true strain, the Arrhenius constitutive model is modified to predict the flow stress, which is in good agreement with the experiment. This indicates that the modified Arrhenius constitutive model can accurately predict and analyze the hot deformation behavior of the as-cast Ti-45Al-9Nb alloy.
\end{abstract}

K e y w o r d s: high Nb containing TiAl alloy, hot compression test, dynamic softening model, modified Arrhenius constitutive model, stress prediction

\section{Introduction}

The high-temperature deformation behavior of metals and alloys are generally complex during the hot forming process [1-3]. The deformation behavior of metals and alloys can be significantly influenced by deformation mechanisms, such as the work hardening, dynamic recovery, and dynamic recrystallization during the hot deformation process [4-6]. Hot deformation behavior is sensitive to the thermo-mechanical parameters, such as the deformation temperature, strain rate, and strain $[7,8]$. Considerable work has been carried out to understand the hot flow behavior of different materials and to predict the flow stress during hot working $[9,10]$. The constitutive model has been used to describe the hot deformation behavior of metals or alloys [11-13]. The dynamic softening model was developed to describe the dynamic softening stage of the hot deformation process [14]. Lin et al. [15] proposed a modified Arrhenius constitutive model to predict the flow stress of $42 \mathrm{CrMo}$ steel at elevated temperatures by the compensation of strain and strain rate. Besides, the modified Arrhenius model was mentioned to describe the hot deformation behavior of $\mathrm{Cu}-0.4 \mathrm{Mg}$ (wt.\%) alloy [16] and cast A356 aluminum alloy [17].

Due to its low density, high strength, good creep, and oxidation resistance, TiAl alloys have become promising in high-temperature structural material [18-20]. Recently, there are increasing interests in high Nb-containing TiAl alloys, since the improvement in hot workability can be achieved by stabilizing the $\beta$-phase through alloying with $\mathrm{Nb}$ element. However, coarse lamellar colonies form during the solidification of high $\mathrm{Nb}$ containing $\mathrm{TiAl}$ alloys, which may cause inhomogeneous microstructures and bring about anisotropy of mechanical properties [21]. Several stud-

*Corresponding author: tel.: +86-0351-6010022; e-mail address: shuzhizhang@outlook.com 
ies showed that hot working is an effective approach to refine grains and improve the mechanical properties of TiAl alloys $[22,23]$. Therefore, a large number of researches have been made to figure out the deformation parameters of the high Nb-containing TiAl alloys [24, $25]$. However, nearly all of these works paid attention to the calculation of material parameters (stress exponent, activation energy), or just illustrated the dependence of the flow stress on strain rate and temperature by Zenner-Hollomon parameter. Also, the hot working of high $\mathrm{Nb}$ containing TiAl alloys is usually carried out at a high temperature and low strain rate, which causes difficulty in obtaining a stress-strain curve by experiment. Therefore, the study of hot deformation behavior of high $\mathrm{Nb}$ containing TiAl alloys needs a suitable model and approach to predict flow stress at different temperatures and strain rates.

Present work aimed to select a preferable model to describe the relationship of stress and strain in $\mathrm{Ti}-45 \mathrm{Al}-9 \mathrm{Nb}$ (at.\%) alloy by comparing the predicted flow stresses and the experimental ones with the help of dynamic softening model and the modified Arrhenius constitutive model. Besides that, the disadvantages and advantages of the dynamic softening model and the modified Arrhenius constitutive model were discussed. Also, the stress which is hard to be obtained was predicted by a suitable model as well.

\section{Materials and experimental}

The cast ingot of the Ti-45Al-9Nb alloy (in at.\%) was fabricated by a Vacuum Arc Remelting (VAR) furnace. The ingot was remelted 4 times to improve its chemical homogeneity. Hot isostatic pressuring (HIP) was conducted for $3 \mathrm{~h}$ at $1553 \mathrm{~K}$ under pressure of $140 \mathrm{MPa}$ in the Ar atmosphere. Cylindrical specimens with a diameter of $8 \mathrm{~mm}$ and a height of $12 \mathrm{~mm}$ were machined from the cast ingot. The isothermal compression tests were conducted on the Gleeble-3500 thermomechanical simulator. Three different strain rates $\left(0.01,0.05\right.$, and $\left.0.1 \mathrm{~s}^{-1}\right)$ and four different deformation temperatures $(1473,1498,1523$, and $1548 \mathrm{~K}$ ) were used in the hot compression tests. Microstructural characterization was performed by Quanta 200FEG field-emission scanning electron microscopy (SEM) using backscattered electrons.

\section{Results and discussion}

\subsection{Initial microstructure}

The measured chemical composition taken from the different positions marked with red crosses in Fig. $1 \mathrm{~b}$ is summarized in Table 1 . Figure 1 shows the microstructure of the as-cast Ti-45Al-9Nb alloy. The
Ta ble 1. The chemical composition at different positions in as-cast $\mathrm{Ti}-45 \mathrm{Al}-9 \mathrm{Nb}$ alloy (at.\%)

\begin{tabular}{cccc}
\hline Position & $\mathrm{Ti}$ & $\mathrm{Al}$ & $\mathrm{Nb}$ \\
\hline $\mathrm{A}$ & 49.73 & 39.01 & 11.26 \\
$\mathrm{~B}$ & 43.17 & 48.53 & 8.3 \\
\hline
\end{tabular}
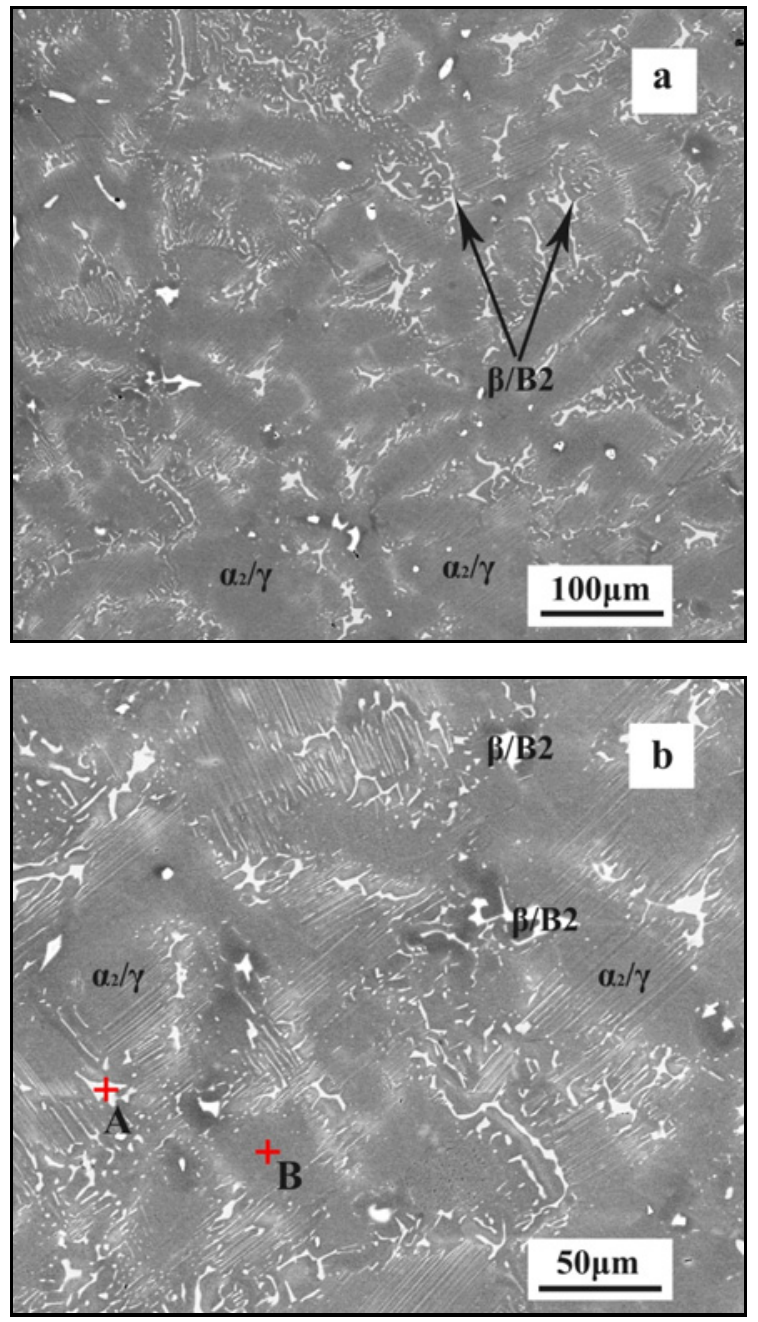

Fig. 1. Microstructures of as-cast Ti-45Al-9Nb alloy: (a) SEM image in low magnification and (b) SEM image in high magnification.

dark phase in Fig. 1a is the $\gamma(\mathrm{TiAl})$ phase, and the white phase is $\beta / \mathrm{B} 2$. The grey contrast in lamellar colonies is $\alpha\left(\mathrm{Ti}_{3} \mathrm{Al}\right)$ phase, which is difficult to observe due to its lower content. As shown in Fig. 1b, the microstructure is mainly composed of coarse $\alpha_{2} / \gamma$ lamellar colonies with average colony sizes larger than $50 \mu \mathrm{m}$. Also, a long striped $\beta / \mathrm{B} 2$ phase can be observed at the boundary of lamellar colonies, which are similar to those observed by Gabalcová and Lapin [26] and Zollinger et al. [27] in Ti-45.9Al-8Nb (at.\%) alloy. 

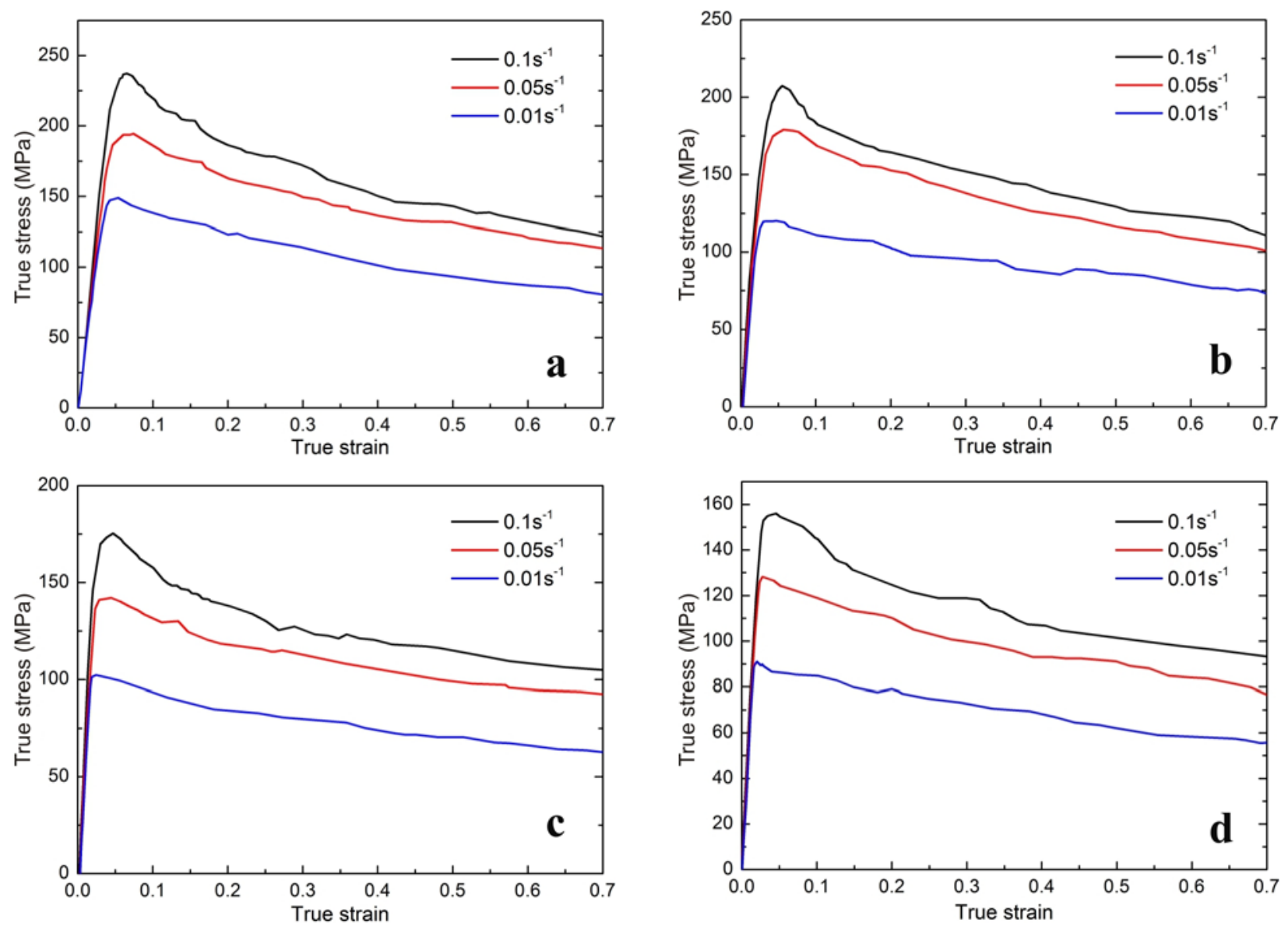

Fig. 2. True stress-true strain curves of the Ti-45Al-9Nb alloy: (a) $1473 \mathrm{~K}$, (b) $1498 \mathrm{~K}$, (c) $1523 \mathrm{~K}$, and (d) $1548 \mathrm{~K}$.

\subsection{Flow behavior}

True stress-true strain curves of the $\mathrm{Ti}-45 \mathrm{Al}-9 \mathrm{Nb}$ alloy obtained from isothermal compression tests at temperatures ranging from 1473 to $1548 \mathrm{~K}$ with strain rates from 0.01 to $0.1 \mathrm{~s}^{-1}$ are shown in Fig. 2. It is revealed that the flow stress is sensitive to the deformation temperature and strain rate. The flow stress decreases with the increase of deformation temperature and decrease of strain rate. All flow curves exhibit strain hardening at the initial stage of deformation, followed by continuous strain softening, and finally, no obvious steady state. It is easy to notice the oscillation of the flow curve in the softening stage. This oscillation can be explained by the interaction between strain hardening and dynamic recrystallization [28].

\subsection{Microstructural evolution}

The microstructure evolution of as-cast Ti-45Al$-9 \mathrm{Nb}$ alloy during hot deformation is shown in Fig. 3. Under the same strain rate of $0.01 \mathrm{~s}^{-1}$, the effect of hot compression temperatures on deformed microstructure can be observed from Figs. 3a-d. At $1200^{\circ} \mathrm{C}$, the microstructure is composed of coarse lamellar colonies and the $\beta / \mathrm{B} 2$ phase. No obvious deformation occurred in the lamellar colonies. However, the microstructure of $\mathrm{Ti}-45 \mathrm{Al}-9 \mathrm{Nb}$ alloy significantly changes with the fine dynamic recrystallization (DRX) $\gamma$ grains produced at the boundary of the lamellar colony due to the decomposition of $\alpha_{2} / \gamma$ lamellas during the compression at $1225^{\circ} \mathrm{C}$, as shown in Fig. 3b. DRX $\gamma$ grains grow with the temperature increased from 1225 to $1275^{\circ} \mathrm{C}$. At a higher temperature of $1275^{\circ} \mathrm{C}$, the coarsening of $\gamma$ laths enlarges the spacing of the $\alpha_{2} / \gamma$ lamellae. At the same time, the precipitation of acicular $\gamma$ grains from the $\beta / \mathrm{B} 2$ phase is observed in Fig. 3d. Also, at the same temperature of $1250^{\circ} \mathrm{C}$, the effect of strain rates on deformed microstructure can be seen in Figs. 3e,f. At a high strain rate of $0.1 \mathrm{~s}^{-1}$, the bending of lamellar colonies is observed, but the breaking of lamellas is limited due to the shorter deformation time, as shown in Fig. 3e. The decomposition degree of $\alpha_{2} / \gamma$ lamellae increases with the decrease of strain rate. At a strain rate of $0.05 \mathrm{~s}^{-1}$, many DRX $\gamma$ grains are observed in Fig. 3f. In summary, the degree of decomposition of $\alpha_{2} / \gamma$ lamellae and dynamic recrystallization of $\gamma$ grains increases with the increasing temperature and decreasing strain rate. 

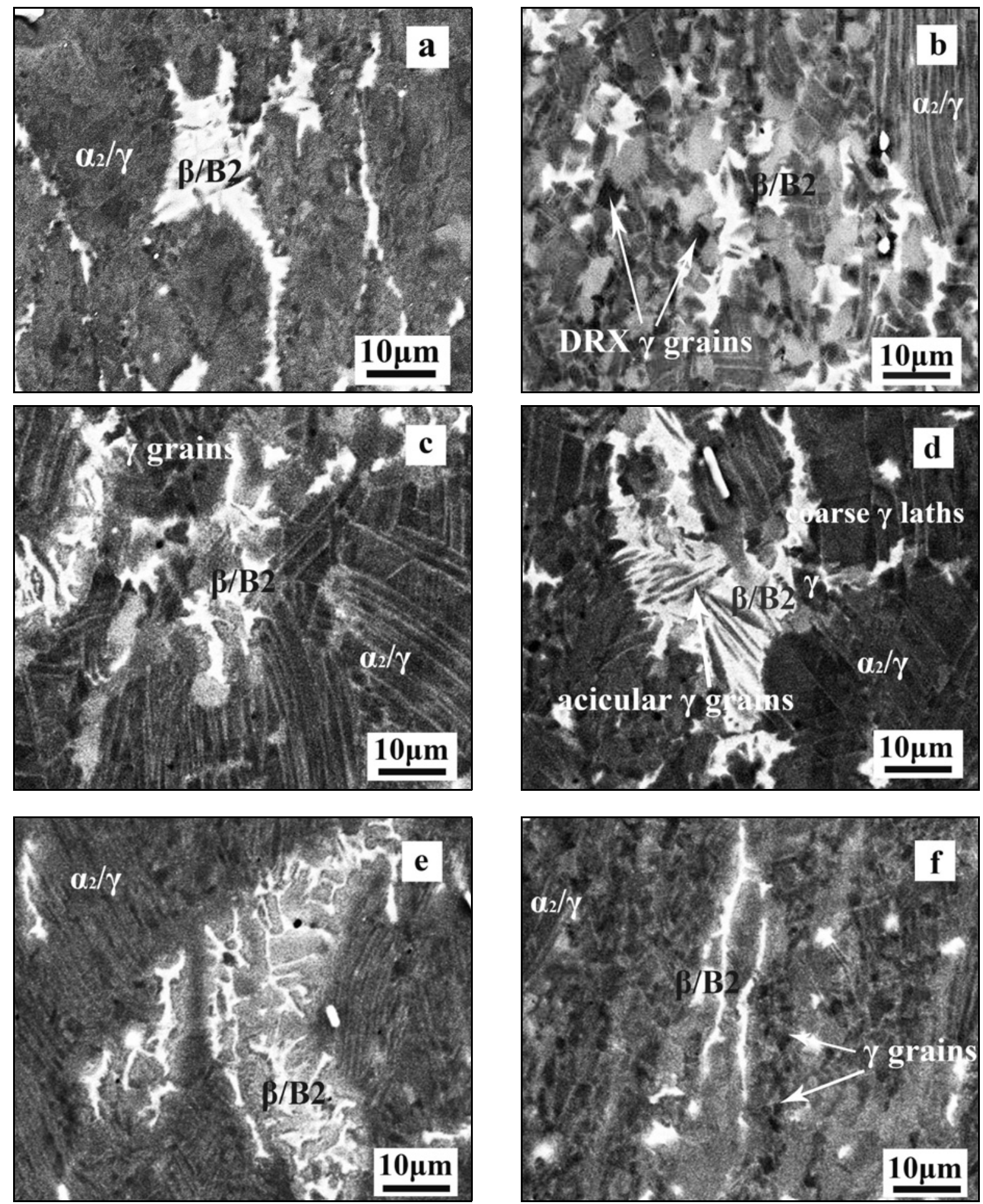

Fig. 3. Microstructures of as-cast Ti-45Al-9Nb alloy hot compressed at: (a) $1200^{\circ} \mathrm{C} / 0.01 \mathrm{~s}^{-1}$, (b) $1225^{\circ} \mathrm{C} / 0.01 \mathrm{~s}^{-1}$, (c) $1250{ }^{\circ} \mathrm{C} / 0.01 \mathrm{~s}^{-1}$, (d) $1275^{\circ} \mathrm{C} / 0.01 \mathrm{~s}^{-1}$, (e) $1250{ }^{\circ} \mathrm{C} / 0.1 \mathrm{~s}^{-1}$, and (f) $1250^{\circ} \mathrm{C} / 0.05 \mathrm{~s}^{-1}$. The compression axis is vertical.

\subsection{Constitutive equation}

The constitutive relationship between the flow stress, strain rate, and deformation temperature during the hot deformation can be described by following Arrhenius equations (Eqs. (1)-(3)). The Hyperbolic-sine law (Eq. (3)), proposed by Sellars [29], is more suitable over a wide range to describe the flow 

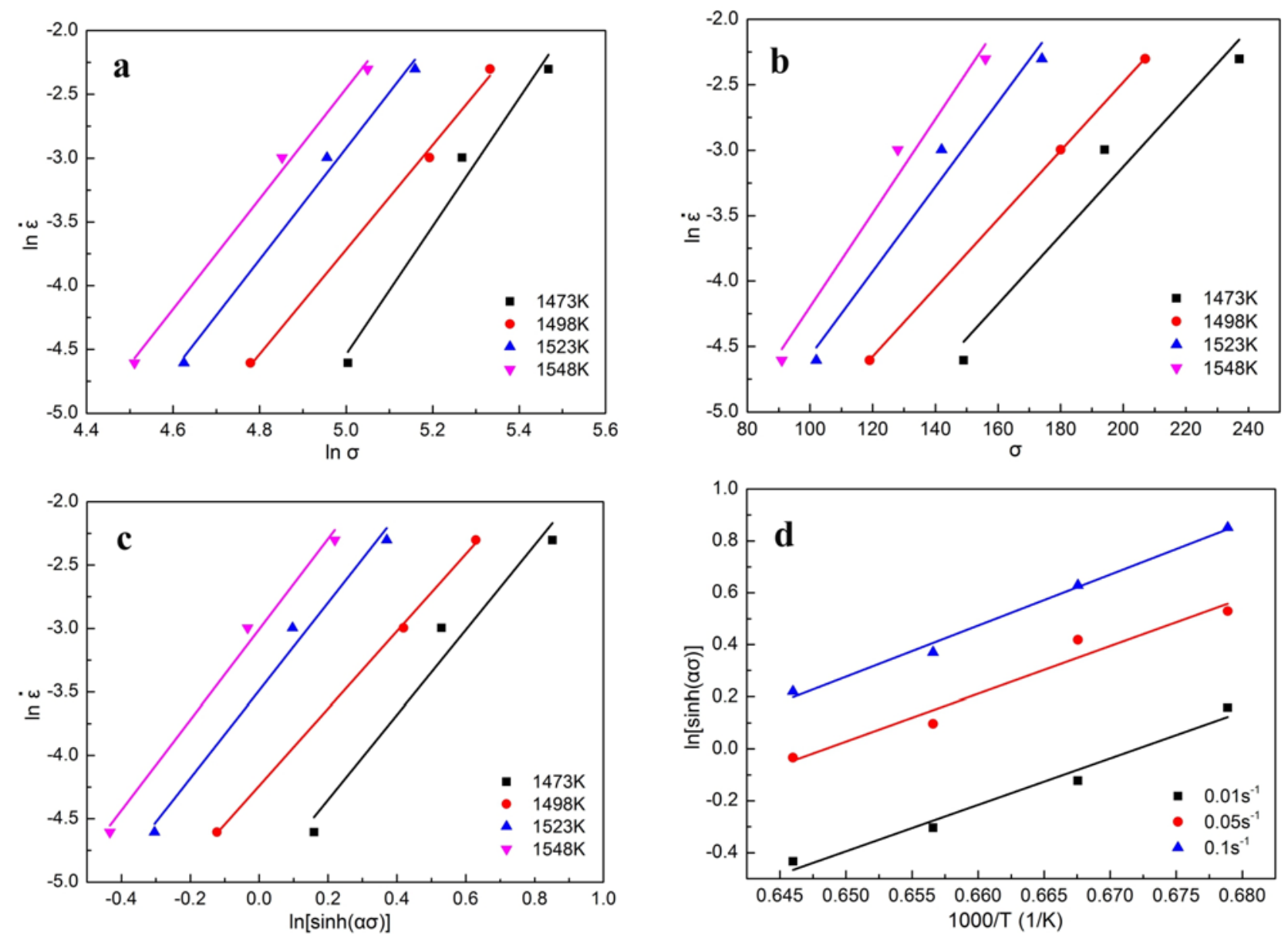

Fig. 4. Relationship curves of the Ti-45Al-9Nb alloy for (a) $\ln \dot{\varepsilon}$ vs. $\ln \sigma$, (b) $\ln \dot{\varepsilon}$ vs. $\sigma$, (c) $\ln \dot{\varepsilon}$ vs. $\ln [\sinh (\alpha \sigma)]$, and (d) $\ln [\sinh (\alpha \sigma)]$ vs. $1 / T$.

behavior:

$$
\begin{gathered}
\dot{\varepsilon}=A_{1} \sigma^{n 1} \exp \left(-\frac{Q}{R T}\right), \quad \alpha \sigma<0.8, \\
\dot{\varepsilon}=A_{2} \exp (\beta \sigma) \exp \left(-\frac{Q}{R T}\right), \quad \alpha \sigma>1.2, \\
\dot{\varepsilon}=A[\sinh (\alpha \sigma)]^{n} \exp \left(-\frac{Q}{R T}\right), \quad \text { for all } \alpha \sigma,
\end{gathered}
$$

where $\dot{\varepsilon}$ is the strain rate $\left(\mathrm{s}^{-1}\right), \sigma$ is the flow stress (MPa), $Q$ is the activation energy for hot deformation $\left(\mathrm{kJ} \mathrm{mol}^{-1}\right), R$ is the gas constant $\left(8.31 \mathrm{~J} \mathrm{~mol}^{-1} \mathrm{~K}^{-1}\right)$, $T$ is the deformation temperature $(\mathrm{K}), n$ is the stress exponent, $A$ and $\alpha$ are the material constants; $\alpha=$ $\beta / n_{1}(\mathrm{MPa})$.

To illustrate the dependence of the flow stress on strain rate and temperature, the Zenner-Hollomon parameter $(Z)$ is used, and their hyperbolic sine relationship can be represented as follows:

$$
Z=\dot{\varepsilon} \exp \left(\frac{Q}{R T}\right)=A[\sinh (\alpha \sigma)]^{n} .
$$

The activation energy $Q$ can be calculated by a transformation of Eq. (4):

$$
Q=R\left\{\frac{\partial \ln \dot{\varepsilon}}{\partial \ln \left[\sinh \left(\alpha \sigma_{\mathrm{p}}\right)\right]}\right\}_{T}\left\{\frac{\partial \ln \left[\sinh \left(\alpha \sigma_{\mathrm{p}}\right)\right]}{\partial(1 / T)}\right\}_{\dot{\varepsilon}},
$$

where $\sigma_{\mathrm{p}}$ is the peak flow stress $(\mathrm{MPa})$.

Parameters $n_{1}, \beta$ can be calculated by the mean slopes of $\ln \dot{\varepsilon}$ vs. $\ln \sigma$ and $\ln \dot{\varepsilon}$ vs. $\sigma$, respectively. Then the value of $\alpha$ is also obtained by the ratio of $\beta / n_{1}$. From the mean slopes of $\ln \dot{\varepsilon}$ vs. $\ln [\sinh (\alpha \sigma)]$ and $\ln [\sinh (\alpha \sigma)]$ vs. $1 / T$ curves, the stress exponent $n$ and the deformation activation energy $Q$ can be worked out. Figure 4 shows the relationships of $\ln \dot{\varepsilon}$ vs. $\ln \sigma$, $\ln \dot{\varepsilon}$ vs. $\sigma, \ln \dot{\varepsilon}$ vs. $\ln [\sinh (\alpha \sigma)]$, and $\ln [\sinh (\alpha \sigma)]$ vs. $1 / T$ at peak stresses. The values of $\alpha, n$, and $Q$ are determined as $0.0067 \mathrm{MPa}^{-1}, 3.35$, and $524.89 \mathrm{~kJ} \mathrm{~mol}^{-1}$, respectively. By substituting the calculated values of $\alpha, n$, and $Q$ into Eq. (3), the value of $A$ can be determined to be $\mathrm{e}^{38.03}$. So, the constitutive equation of $\mathrm{Ti}-45 \mathrm{Al}-9 \mathrm{Nb}$ alloy can be expressed as:

$$
\dot{\varepsilon}=\mathrm{e}^{38.03}\left[\sinh \left(0.0067 \sigma_{\mathrm{p}}\right)\right]^{3.35} \exp \left(-\frac{524.89}{R T}\right) .
$$




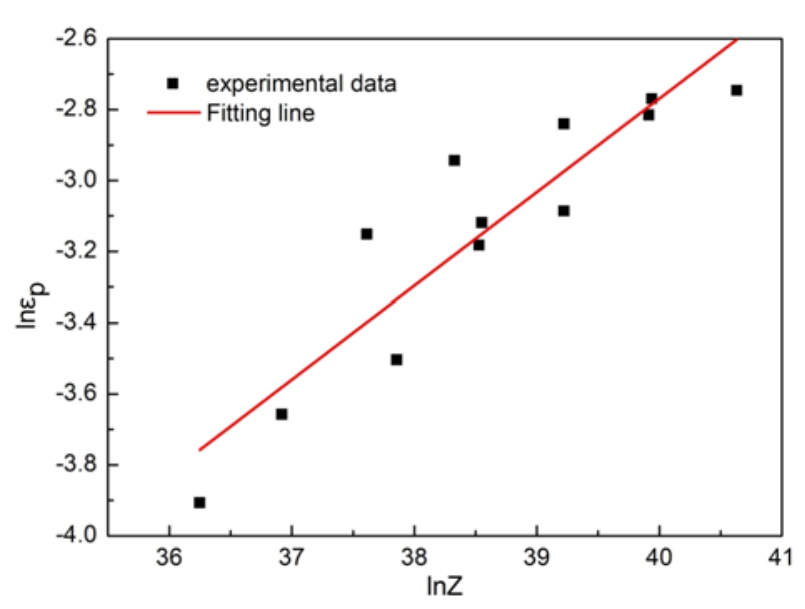

Fig. 5. The relationship between $\ln \varepsilon_{\mathrm{p}}$ and $\ln Z$.

\subsection{Dynamic softening model}

The obvious dynamic softening behavior of $\mathrm{TiAl}$ alloy often appears when the true strain is more than the peak strain. Dynamic softening model [14], which takes the influence of peak stress and strain into account, can be used to evaluate the flow stress, as shown in Eq. (7):

$$
\frac{\sigma}{\sigma_{\mathrm{p}}}=\left[\frac{\varepsilon}{\varepsilon_{\mathrm{p}}} \exp \left(1-\frac{\varepsilon}{\varepsilon_{\mathrm{p}}}\right)\right]^{c},
$$

where $\sigma$ is the true stress, $\varepsilon$ is the true strain, $\sigma_{\mathrm{p}}$ is the peak stress, $\varepsilon_{\mathrm{p}}$ is the peak strain, and $c$ is the material constant.

Peak stress can be obtained from the constitutive equation (6). The equations describing the relationship between the peak stress and the Zener-Hollomon parameter are listed as follows:

$$
\begin{gathered}
\sigma_{\mathrm{p}}=\frac{1}{0.0067} \ln \left\{\left(\frac{Z}{\mathrm{e}^{38.03}}\right)^{\frac{1}{3.35}}+\left[\left(\frac{Z}{\mathrm{e}^{38.03}}\right)^{\frac{1}{3.35}}+1\right]^{\frac{1}{2}}\right\}, \\
Z=\dot{\varepsilon} \exp \left(\frac{524.89}{R T}\right) .
\end{gathered}
$$

Peak strain can also be expressed as the function of the Zener-Hollomon parameter:

$$
\varepsilon_{\mathrm{p}}=k Z^{m},
$$

where $k$ and $m$ are material constants. Taking the logarithm of both sides of Eq. (7) gives:

$$
\ln \varepsilon_{\mathrm{p}}=m \ln Z+\ln k .
$$

By the linear fitting method (shown in Fig. 5), the values of $k$ and $m$ can be determined as $1.64 \times 10^{-6}$ and 0.2637 , respectively.
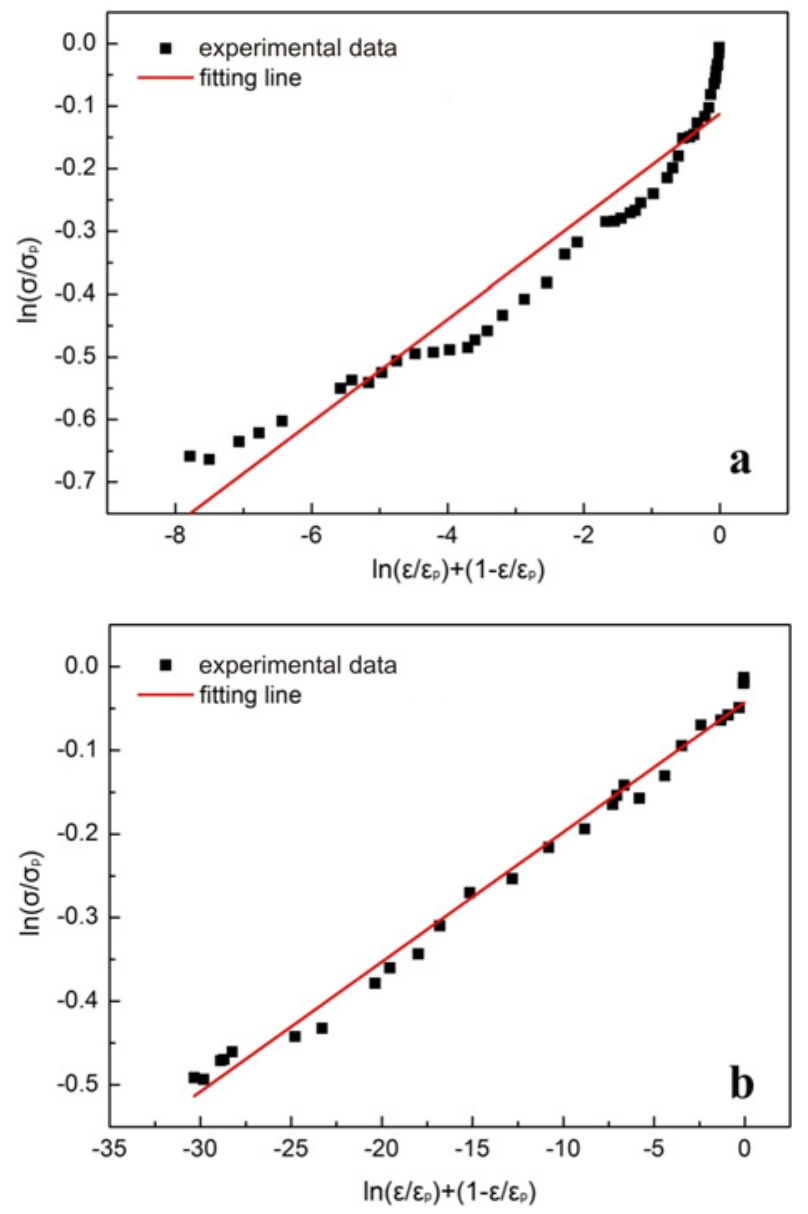

Fig. 6. The relationship between $\ln \left(\sigma / \sigma_{\mathrm{p}}\right)$ and $\left[\ln \left(\varepsilon / \varepsilon_{\mathrm{p}}\right)+\right.$ $\left.\left(1-\varepsilon / \varepsilon_{\mathrm{p}}\right)\right]$ under different conditions: (a) $1473 \mathrm{~K}, 0.1 \mathrm{~s}^{-1}$ and (b) $1548 \mathrm{~K}, 0.01 \mathrm{~s}^{-1}$.

So, the peak strain of the studied Ti-45Al-9Nb alloy can be evaluated by:

$$
\varepsilon_{\mathrm{p}}=1.64 \times 10^{-6} Z^{0.2637} \text {. }
$$

Taking the logarithm of both sides of Eq. (7) gives:

$$
\ln \left(\frac{\sigma}{\sigma_{\mathrm{p}}}\right)=c\left[\ln \left(\frac{\varepsilon}{\varepsilon_{\mathrm{p}}}\right)+\left(1-\frac{\varepsilon}{\varepsilon_{\mathrm{p}}}\right)\right] .
$$

According to calculated peak strain and peak stress, the material constant $c$ can be obtained from Eq. (13) by using the linear fitting method. Figure 6 shows the relationship between $\ln \left(\sigma / \sigma_{\mathrm{p}}\right)$ and $\left[\ln \left(\varepsilon / \varepsilon_{\mathrm{p}}\right)+\left(1-\varepsilon / \varepsilon_{\mathrm{p}}\right)\right]$ under different conditions. The experimental data based on the linear fitting method are different under two different deformation conditions. At the temperature of $1473 \mathrm{~K}$ and the strain rate of $0.1 \mathrm{~s}^{-1}$, the distribution of the experimental data is not strictly along the straight line, illustrating the relationship between $\ln \left(\sigma / \sigma_{\mathrm{p}}\right)$ and $\left[\ln \left(\varepsilon / \varepsilon_{\mathrm{p}}\right)+\left(1-\varepsilon / \varepsilon_{\mathrm{p}}\right)\right]$ 
Table 2. The values of material constant $c$ under all the tested conditions

\begin{tabular}{ccccc}
\hline \multirow{2}{*}{ Strain rate $\left(\mathrm{s}^{-1}\right)$} & \multicolumn{4}{c}{ Deformation temperature $(\mathrm{K})$} \\
\cline { 2 - 5 } & 1473 & 1498 & 1523 & 0.01551 \\
\hline 0.01 & 0.05879 & 0.03261 & 0.01926 & 0.02339 \\
0.05 & 0.06297 & 0.06125 & 0.03046 & 0.04029 \\
\hline 0.1 & 0.08199 & 0.06205 & 0.03896 & \\
\hline
\end{tabular}
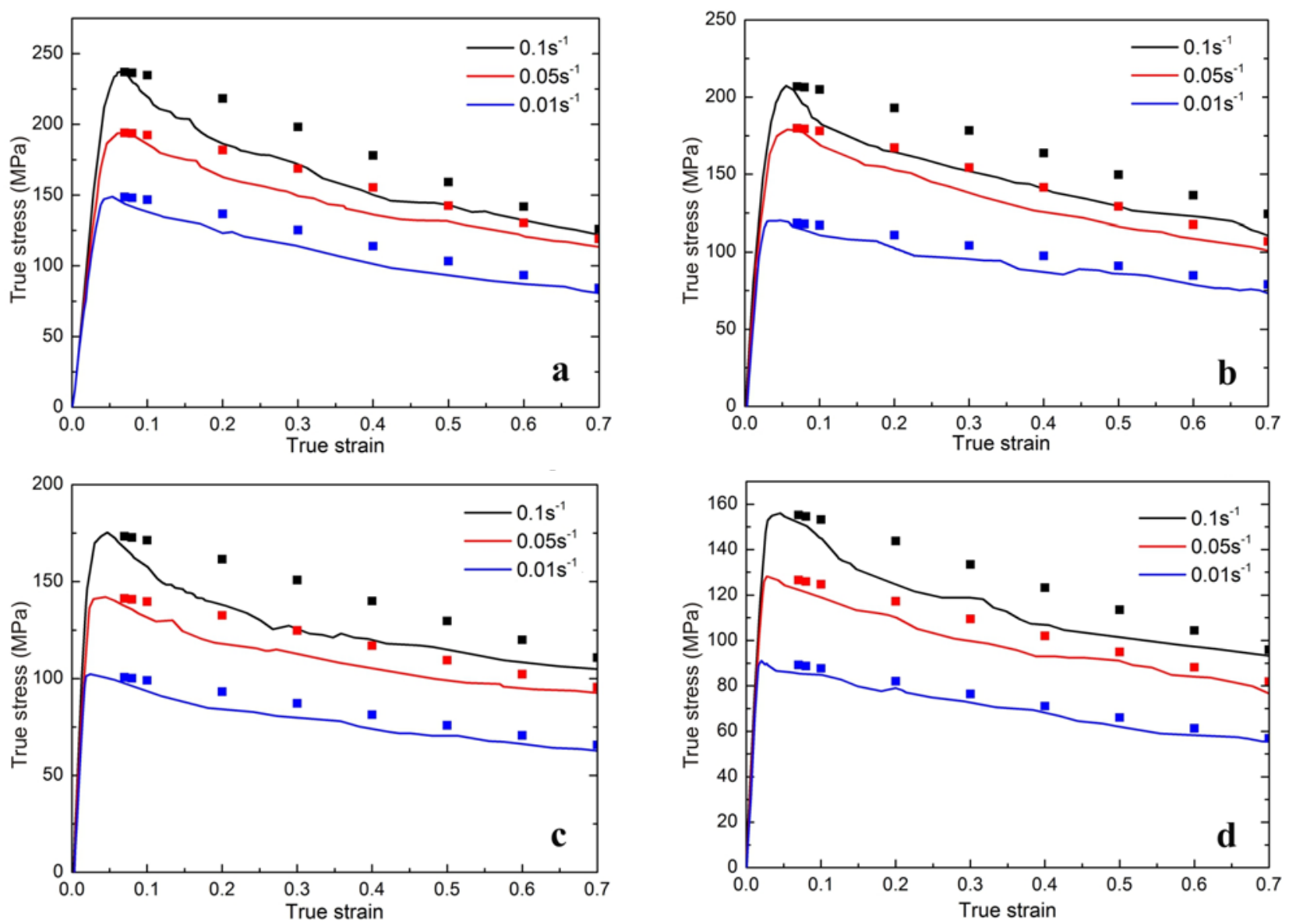

Fig. 7. The comparisons between the experimental and predicted flow stress with the dynamic softening model under the different conditions: (a) $1473 \mathrm{~K}$, (b) $1498 \mathrm{~K}$, (c) $1523 \mathrm{~K}$, and (d) $1548 \mathrm{~K}$.

is nonlinear, as shown in Fig. 6a. From Fig. 6b, it is easy to find the linear distribution of experimental data when the deformed temperature is $1548 \mathrm{~K}$, and the strain rate is $0.01 \mathrm{~s}^{-1}$.

By substituting the strain and corresponding flow stress under different conditions into Eq. (13), the material constant $c$ can be obtained by the linear fitting method, as shown in Table 2.

With the help of Eqs. (8) and (12), $\sigma_{\mathrm{p}}, \varepsilon_{\mathrm{p}}$ can be obtained under different temperatures and strain rates. Substituting the peak stress, peak strain, and the material constant $c$ from Table 2 into Eq. (7), the flow stress at a specific strain can be evaluated. To evaluate the dynamic softening model, the com- parisons between the measured flow stresses and predicted results are carried out, as shown in Fig. 7.

From Fig. 7, it can be found that the deviation between experimental and predicted data is large when the strain rate is $0.1 \mathrm{~s}^{-1}$. The maximum deviation value even reaches $20 \%$. Also, the deviation decreases with the decrease of strain rate and the increase in temperature. The deviation between experiment and predicted data could be explained by the material constant $c$ which is obtained by the slope of the fitting line of $\ln \left(\sigma / \sigma_{\mathrm{p}}\right)$ and $\left[\ln \left(\varepsilon / \varepsilon_{\mathrm{p}}\right)+\left(1-\varepsilon / \varepsilon_{\mathrm{p}}\right)\right]$. The relationship of $\ln \left(\sigma / \sigma_{\mathrm{p}}\right)$ and $\left[\ln \left(\varepsilon / \varepsilon_{\mathrm{p}}\right)+\left(1-\varepsilon / \varepsilon_{\mathrm{p}}\right)\right]$ is nonlinear under the lower temperature and the higher strain rate (Fig. 6a). That is to say that the parameter $c$ is not 
a constant value. Therefore, the constant $c$ in a dynamic softening model does not accurately reflect the relationship of $\ln \left(\sigma / \sigma_{\mathrm{p}}\right)$ and $\left[\ln \left(\varepsilon / \varepsilon_{\mathrm{p}}\right)+\left(1-\varepsilon / \varepsilon_{\mathrm{p}}\right)\right]$. Substituting the acquired constant $c$ into Eq. (7), a large deviation between experimental and predicted flow stress is inevitable. With the increase of temperature and the decrease of strain rate, the relationship of $\ln \left(\sigma / \sigma_{\mathrm{p}}\right)$ and $\left[\ln \left(\varepsilon / \varepsilon_{\mathrm{p}}\right)+\left(1-\varepsilon / \varepsilon_{\mathrm{p}}\right)\right]$ is linear (Fig. 6b). The parameter $c$ can be regarded as a constant value at high temperatures and low strain rates. So the deviation between experimental and predicted flow stress is little at high temperatures and low strain rates. Previous reports showed that dynamic softening is the main mechanism at a lower strain rate $[4,13]$. This can explain why the predicted results are close to the experimental flow stresses at a lower strain rate with the help of a dynamic softening model. From the above discussion, we can find that the effect of strain on material parameter $c$ is complicated, and the parameter $c$ could not be regarded as a constant at all. Hence, the invariable material constant of $c$ is not accurate in the dynamic softening model to describe the relationship between strain and stress. To predict the
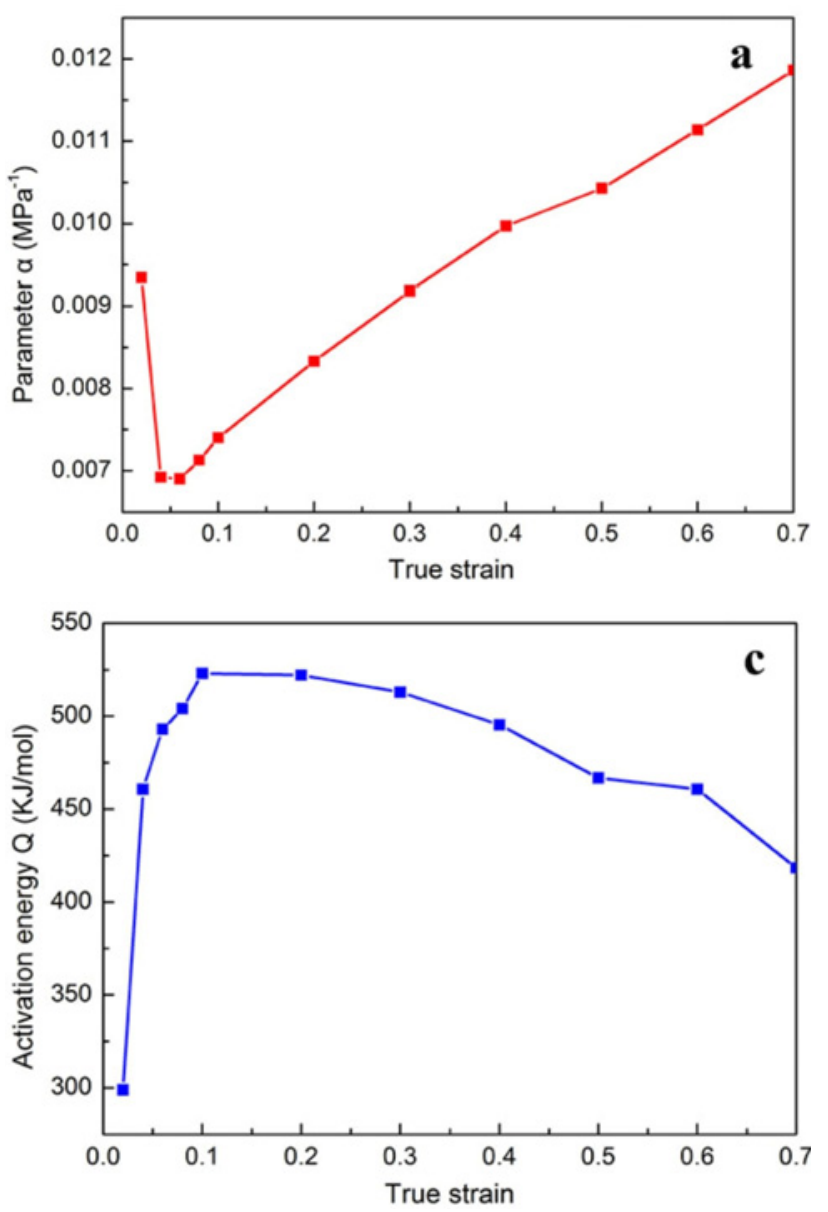

flow stress accurately, the model containing many variable parameters should be used.

\subsection{Modified Arrhenius constitutive model}

It can be seen from the constitutive equation (Eq. (3)) $\dot{\varepsilon}=A[\sinh (\alpha \sigma)]^{n} \exp \left(-\frac{Q}{R T}\right)$, the flow stress is related to the deformation conditions and material parameters. Apart from the strain rate and temperature, the effect of strain on the flow stress should not be neglected. To predict the flow stress accurately, the parameters $\alpha, n, A$, and $Q$ need to be evaluated at different strains within the range of 0.02-0.7. Substituting the flow stress under a specific strain into Eq. (3), values of $\alpha$ and $n$ can be obtained by the ratio of $\beta / n_{1}$ and mean slopes of $\ln \dot{\varepsilon}$ vs. $\ln [\sinh (\alpha \sigma)]$ curves, respectively. The value of $Q$ could be acquired through the mean slopes of $\ln \dot{\varepsilon}$ vs. $\ln [\sinh (\alpha \sigma)]$ and $\ln [\sinh (\alpha \sigma)]$ vs. $1 / T$ curves. Substituting the calculated values of $\alpha, n$, and $Q$ into Eq. (3), the parameter $A$ can be determined through the mean intercept of $\ln \dot{\varepsilon}$ vs. $\ln [\sinh (\alpha \sigma)]$ curves.
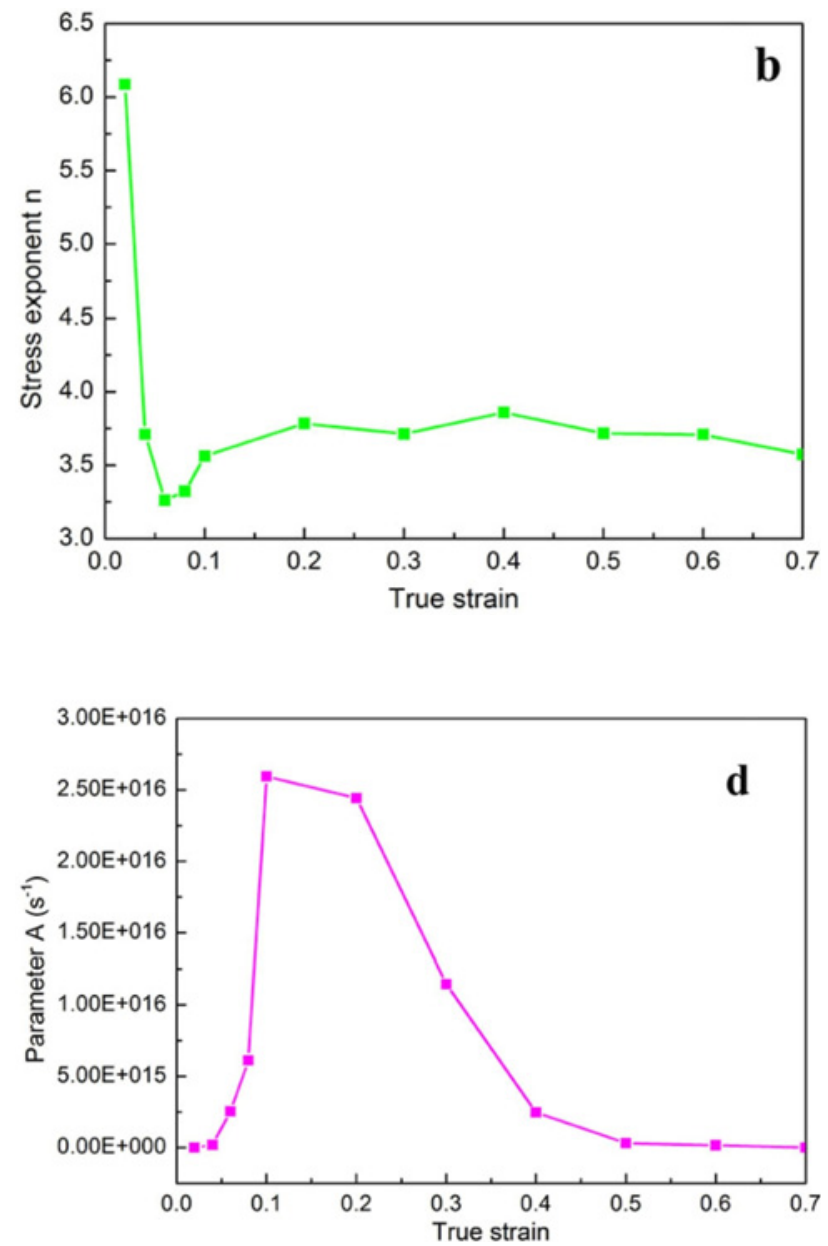

Fig. 8. The relationships between (a) parameter $\alpha$, (b) stress exponent $n$, (c) deformation activation energy $Q$, and (d) parameter $A$ and true strain. 

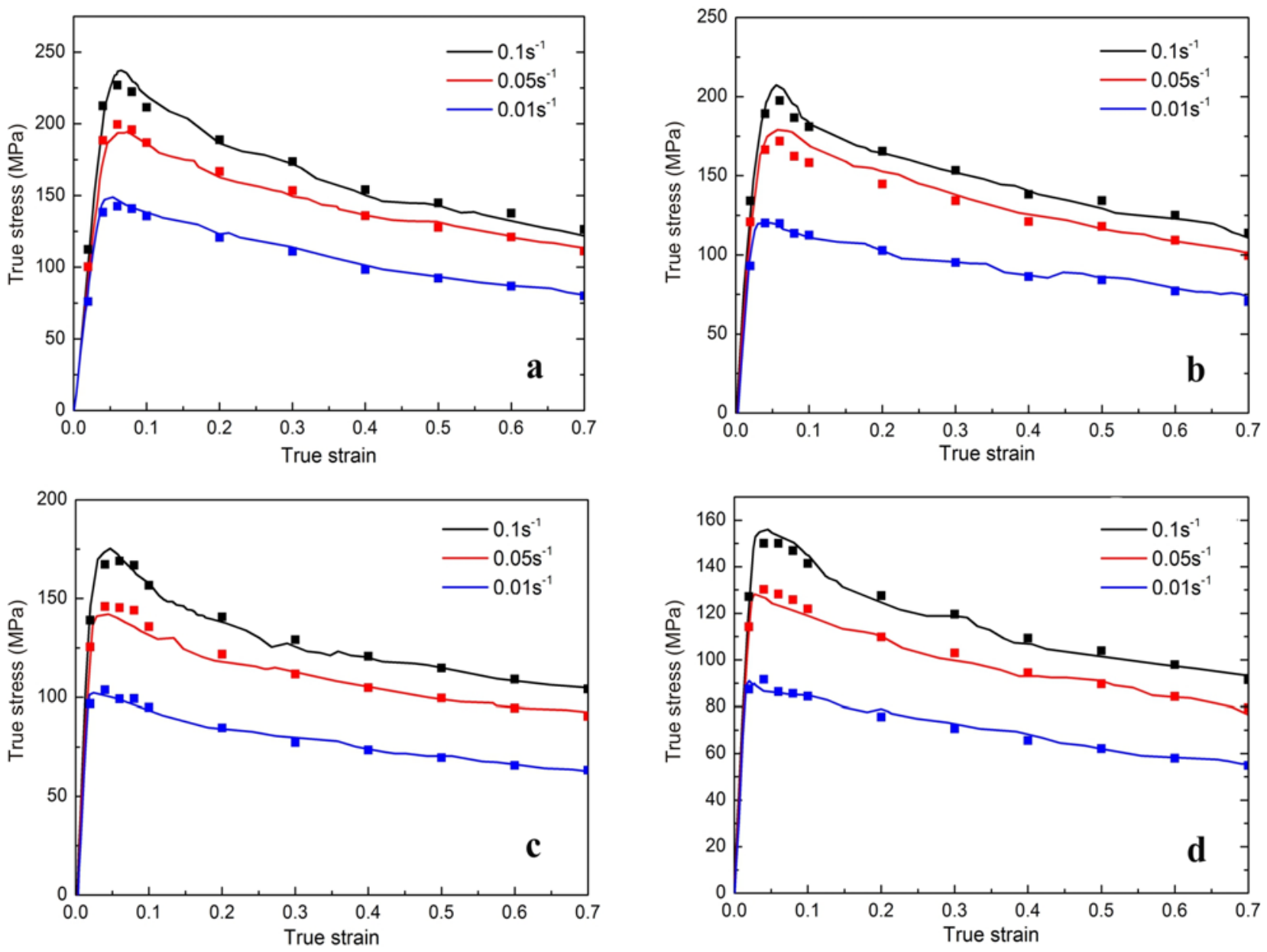

Fig. 9. The comparisons between the measured and predicted flow stress through the modified Arrhenius constitutive model under different conditions: (a) $1473 \mathrm{~K}$, (b) $1498 \mathrm{~K}$, (c) $1523 \mathrm{~K}$, and (d) $1548 \mathrm{~K}$.

To figure out the calculated value of flow stress, the hot-working parameters $\alpha, n, A$, and $Q$ as a function of true strain are shown in Fig. 8. The value of parameter $\alpha$ observed from Fig. 8a decreases at the initial state, followed by a continuous increase. Stress exponent $n$ from Fig. 8b decreases rapidly, and then maintains at a stable range. However, the activation energy $Q$ in Fig. 8c and the parameter $A$ in Fig. 8d show inverse behavior. Activation energy $Q$ increases significantly, followed by a linear decrease. The value of $A$ increases first, then decreases and finally stabilizes at $10^{12}$ from the strain of 0.5 .

In order to further acquire the exact values of the parameters $\alpha, n, A$, and $Q$ in the whole deformation, these parameters can be presented as the polynomial function of the true strain, i.e. Eqs. (14a)-(14d):

$$
\begin{array}{r}
\alpha=B_{0}+B_{1} \varepsilon+B_{2} \varepsilon^{2}+B_{3} \varepsilon^{3}+B_{4} \varepsilon^{4}+B_{5} \varepsilon^{5}, \quad(14 \mathrm{a}) \\
n=C_{0}+C_{1} \varepsilon+C_{2} \varepsilon^{2}+C_{3} \varepsilon^{3}+C_{4} \varepsilon^{4}+C_{5} \varepsilon^{5}, \quad(14 \mathrm{~b}) \\
\ln A=D_{0}+D_{1} \varepsilon+D_{2} \varepsilon^{2}+D_{3} \varepsilon^{3}+D_{4} \varepsilon^{4}+D_{5} \varepsilon^{5},(14 \mathrm{c})
\end{array}
$$

$$
Q=E_{0}+E_{1} \varepsilon+E_{2} \varepsilon^{2}+E_{3} \varepsilon^{3}+E_{4} \varepsilon^{4}+E_{5} \varepsilon^{5},
$$

where $B_{i}, C_{i}, D_{i}, E_{i}(i=0,1,2,3,4,5)$ are polynomial coefficients. The polynomial fitting results of $\alpha$, $n, A$, and $Q$ regarding the investigated $\mathrm{Ti}-45 \mathrm{Al}-9 \mathrm{Nb}$ alloy are summarized in Table 3.

According to the constitutive equation, flow stress can be represented as follows:

$$
\sigma=\frac{1}{\alpha} \operatorname{arsinh}\left\{\frac{\dot{\varepsilon}}{A} \exp \left(-\frac{Q}{R T}\right)\right\}^{\frac{1}{n}},
$$

where $\alpha, n, A$, and $Q$ can be obtained from Eq. (14).

Modified Arrhenius constitutive equation (Eq. (15)) is used to comprehensively describe and predict the flow stress. Substituting the calculated values of $\alpha, n, A$, and $Q$ into the Eq. (15), the true stress under a specific deformation temperature and strain rate is evaluated. Figure 9 describes the comparison between the measured and predicted flow stress obtained through the constitutive model under different deformation conditions. It can be seen that the predicted flow stress is very close to the measured flow stress, 
Ta ble 3. Polynomial fitting results for calculating $\alpha, n, \ln A$, and $Q$

\begin{tabular}{|c|c|c|c|c|}
\hline$i$ & $B_{i}$ & $C_{i}$ & $D_{i}$ & $E_{i}$ \\
\hline 0 & 0.01003 & 7.00074 & 12.77103 & 221.97503 \\
\hline 1 & -0.0795 & -88.90599 & 534.03715 & 6400.84837 \\
\hline 2 & 0.66947 & 683.97829 & -3652.63103 & -43413.93466 \\
\hline 3 & -2.11397 & -2172.28806 & 10722.20549 & 126581.69135 \\
\hline 4 & 2.93146 & 3043.19049 & -14256.03431 & -167489.97628 \\
\hline 5 & -1.48354 & -1558.6096 & 7007.55348 & 82038.22446 \\
\hline
\end{tabular}

and the experimental results are in good agreement with the predicted flow stress. This satisfactory fitness indicates that the reorganized constitutive model can be used to predict flow stress accurately.

To evaluate the relationship between the experimental data and the predicted flow stress, correlation coefficient $(R)$, and the standard deviation (SD) are used. $R$ and $\mathrm{SD}$ can be calculated by the following Eqs. (16) and (17):

$$
\begin{gathered}
R=\frac{\sum_{i=1}^{N}\left(E_{i}-\bar{E}\right)\left(P_{i}-\bar{P}\right)}{\sqrt{\sum_{i=1}^{N}\left(E_{i}-\bar{E}\right)^{2} \sum_{i=1}^{N}\left(P_{i}-\bar{P}\right)^{2}}}, \\
\mathrm{SD}=\sqrt{\frac{1}{N} \sum_{i=1}^{N}\left(P_{i}-E_{i}\right)^{2}} .
\end{gathered}
$$

Figure 10 is the scatter map of predicted data versus the experimental data in the process of hot deformation. From Fig. 10a, it can be seen that the $R$ and $\mathrm{SD}$ of the dynamic softening model are determined as 0.97724 and 0.01569 , respectively, which illustrates that the agreement between the predicted and the experimental data is not rigorous. To further evaluate the accuracy of the modified Arrhenius constitutive model, the scatter map of the predicted and the experimental data under all the tested conditions is given, as shown in Fig. 10b. For the modified Arrhenius model, the $R$ and SD are determined as 0.98686 and 0.01005 . The high correlation coefficient and the low standard deviation in the linear regression imply the acceptable fitting of predicted data to the experimental data. Therefore, the modified Arrhenius constitutive model has an excellent capability to predict the flow behavior of this alloy.

The hot compression test can be employed to guide the thermoforming process, such as hot forging, hot rolling, and hot extrusion. Hot deformation of high $\mathrm{Nb}$ containing TiAl based alloy is usually operated at temperature above $1523 \mathrm{~K}$. However, hot compressing at high temperature and high strain rate, such as at $1573 \mathrm{~K}$ with a strain rate of $1 \mathrm{~s}^{-1}$, is difficult due to
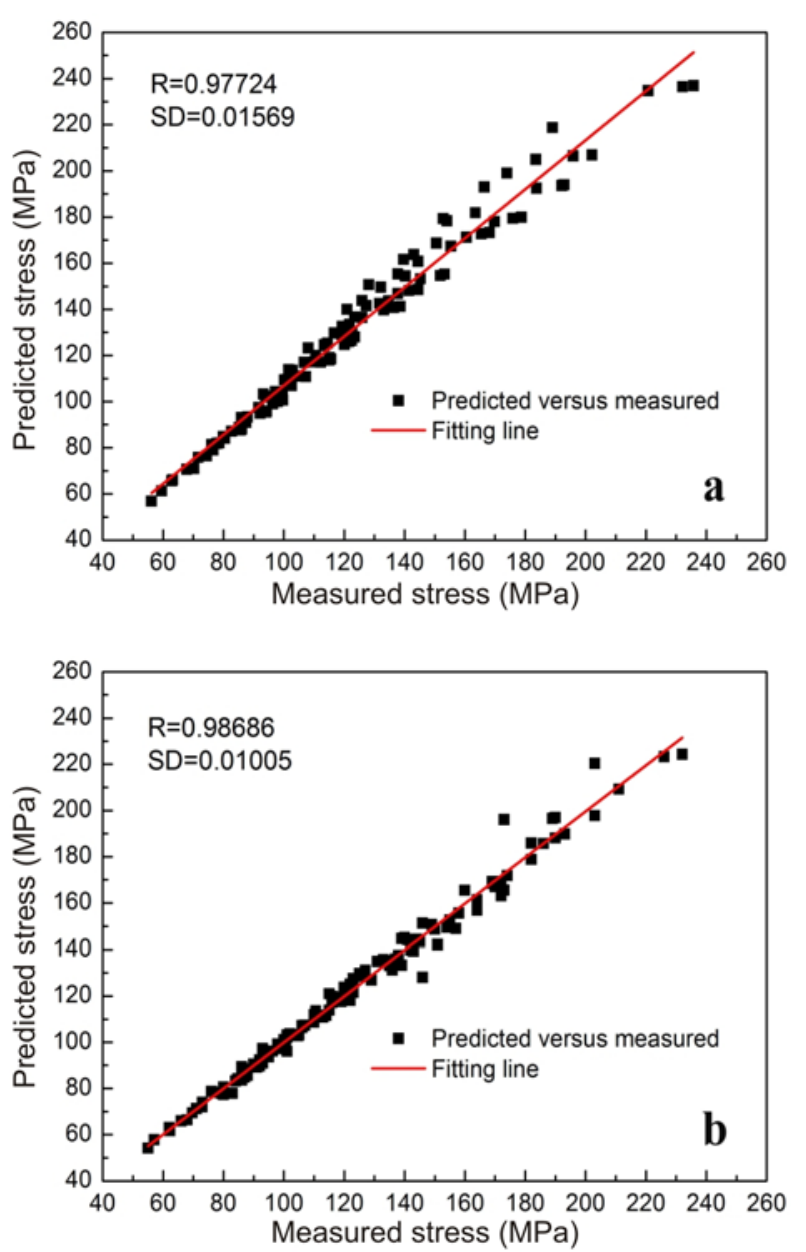

Fig. 10. The scatter map of the predicted versus measured flow stresses during the hot compression process: (a) dynamic softening model and (b) modified Arrhenius model.

thermocouples falling off and press ram bearing capacity as well as equipment and operation staff security. So the stress prediction at elevated temperature $(1573 \mathrm{~K})$ is necessary before the hot compression test. According to the polynomial coefficient obtained from Table 3, the deformation parameters $\alpha, n, A$, and $Q$ can be calculated within the strain range of $0.02-0.1$ (having an interval of 0.02) and 0.1-0.7 (having an interval of 0.1). Substituting the determined values of $\alpha$, $n, A$, and $Q$ into the Eq. (15), the true stresses under 


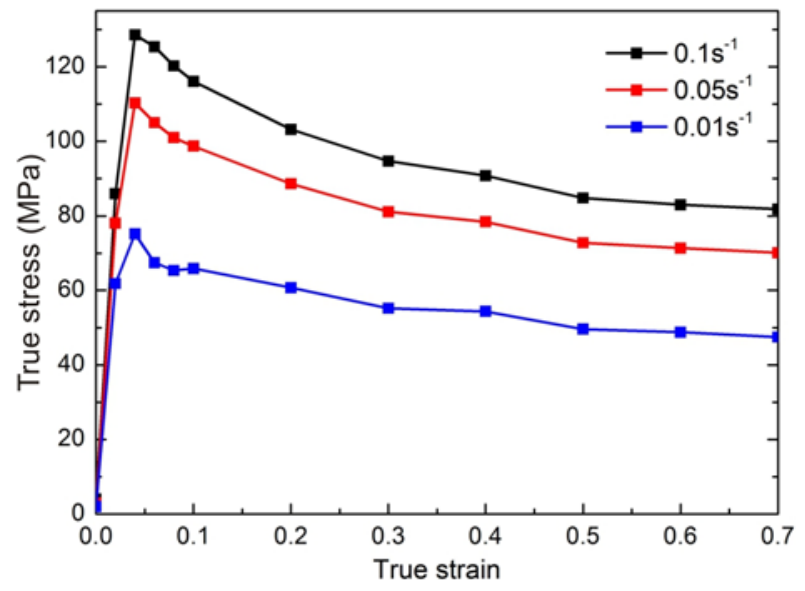

Fig. 11. The flow stress prediction of Ti-45Al-9Nb alloy by the modified Arrhenius constitutive model at $1573 \mathrm{~K}$.

the deformation temperature of $1573 \mathrm{~K}$ and the strain rates of $0.01,0.05$, and 0.1 are predicted. Figure 11 shows the flow stress predicted by the modified Arrhenius constitutive model at $1573 \mathrm{~K}$. Compared with the lower deformation temperature, it can be found that the flow stress of $\mathrm{Ti}-45 \mathrm{Al}-9 \mathrm{Nb}$ alloy decreases at $1573 \mathrm{~K}$. Moreover, similar strain hardening and dynamic softening phenomena also appear. In consideration of the excellent capability of fitting and predicting flow stresses, it is advisable to adopt a modified Arrhenius constitutive model to describe the hot deformation behavior of Ti-45Al-9Nb alloy.

\section{Conclusions}

In this paper, the high-temperature deformation behavior of the $\mathrm{Ti}-45 \mathrm{Al}-9 \mathrm{Nb}$ alloy was investigated by the isothermal compression test. Based on the experimental data, the constitutive equation was established and the activation energy of hot deformation was calculated to be $524.89 \mathrm{~kJ} \mathrm{~mol}^{-1}$ for this alloy. Both dynamic softening model and reorganized constitutive model are used to predict the true flow stresses. At the lower strain rate, there is a good agreement between the predicted and the experimental data with the dynamic softening model. However, the deviation between experimental and predicted data is large when the strain rate is high, and the temperature is low. To predict the flow stress accurately, the modified Arrhenius model is proposed. The modified Arrhenius model has a high correlation coefficient and low standard deviation, which shows the excellent fitting of the predicted and the experimental data. The modified Arrhenius constitutive equation is helpful to model, predict, and analyze the hot deformation process of $\mathrm{Ti}-45 \mathrm{Al}-9 \mathrm{Nb}$ alloy.

\section{Acknowledgements}

The financial support from the National Natural Science Foundation of China (Nos. 51604191, 51604159, 51504153), the Natural Science Foundation of Shanxi Province, China (No. 201701D221075), the State Key Laboratory for Advanced Metal and Materials Foundation (No. 2014-ZD06), and the Special/Youth Foundation of Taiyuan University of Technology (No. 2015QN014) is gratefully acknowledged.

\section{References}

[1] A. Momeni, K. Dehghani, G. R. Ebrahimi, S. Kazemi, Developing the Processing Maps Using the Hyperbolic Sine Constitutive Equation, Metall. Mater. Trans. A 44 (2013) 5567-5576. doi:10.1007/s11661-013-1841-5

[2] Y. C. Lin, X. M. Chen, A critical review of experimental results and constitutive descriptions for metals and alloys in hot working, Mater. Design 32 (2011) 17331759. doi:10.1016/j.matdes.2010.11.048

[3] I. Balasundar, T. Raghu, B. P. Kashyap, Modeling the hot working behavior of near- $\alpha$ titanium alloy IMI 834, Prog. Nat. Sci. Mater. Int. 23 (2013) 598-607. doi:10.1016/i.pnsc.2013.11.004

[4] B. C. Zhao, T. Zhao, G. Y. Li, Q. Lu, The kinetics of dynamic recrystallization of a low carbon vanadiumnitride microalloyed steel, Mater. Sci. Eng. A 604 (2014) 117-121. doi:10.1016/j.msea.2014.03.019

[5] H. Mirzadeh, A. Najafizadeh, Prediction of the critical conditions for initiation of dynamic recrystallization, Mater. Design 31 (2010) 1174-1179. doi:10.1016/j.matdes.2009.09.038

[6] F. Chen, Z. S. Cui, J. Liu, X. X. Zhang, W. Chen, Modeling and simulation on dynamic recrystallization of $30 \mathrm{Cr} 2 \mathrm{Ni} 4 \mathrm{MoV}$ rotor steel using the cellular automaton method, Mater. Sci. Eng. 17 (2009) 075015. doi:10.1088/0965-0393/17/7/075015

[7] C. J. Shi, W. M. Mao, X. G. Chen, Evolution of activation energy during hot deformation of AA7150 aluminum alloy, Mater. Sci. Eng. A 571 (2013) 83-91. doi:10.1016/j.msea.2013.01.080

[8] F. Yin, L. Hua, H. J. Mao, X. H. Han, D. S. Qian, R. Zhang, Microstructural modeling and simulation for GCr15 steel during elevated temperature deformation, Mater. Design 55 (2014) 560-573. doi:10.1016/j.matdes.2013.10.042

[9] W. T. Wang, X. Z. Guo, B. Huang, J. Tao, H. G. Li, W. J. Pei, The flow behaviors of CLAM steel at high temperature, Mater. Sci. Eng. A 599 (2014) 134-140. doi:10.1016/j.msea.2014.01.038

[10] Y. Y. Li, S. D. Zhao, S. Q. Fan, B. Zhong, Plastic properties and constitutive equations of $42 \mathrm{CrMo}$ steel during warm forming process, Mater. Sci. Technol. 30 (2014) 645-652. doi:10.1179/1743284713Y.0000000378

[11] J. Li, B. Gao, S. Tang, B. Liu, Y. Liu, Y. Wang, J. Wang, High temperature deformation behavior of carbon-containing FeCoCrNiMn high entropy alloy, J. Alloy. Compd. 747 (2018) 571-579. doi:10.1016/j.jallcom.2018.02.332 
[12] G. Liu, W. Xie, A. Hadadzadeh, G. Wei, Z. Ma, J. Liu, Y. Yang, W. Xie, X. Peng, M.Wells, Hot deformation behavior and processing map of a superlight dual-phase Mg-Li alloy, J. Alloy Compd. 766 (2018) 460-469. doi:10.1016/j.jallcom.2018.07.024

[13] W. Zhang, Y. Liu, H. Z. Li, Z. Li, H. Wang, B. Liu, Constitutive modeling and processing map for elevated temperature flow behaviors of a powder metallurgy titanium aluminide alloy, J. Mater. Process. Tech. 209 (2009) 5363-5370. doi:10.1016/i.jmatprotec.2009.04.006

[14] Y. C. Lin, K. K. Li, H. B. Li, New constitutive model for high-temperature deformation behavior of inconel 718 superalloy, Mater. Design 74 (2015) 108118. doi:10.1016/j.matdes.2015.03.001

[15] Y. C. Lin., M. S. Chen, J. Zhong, Constitutive modeling for elevated temperature flow behavior of 42CrMo steel, Comput. Mater. Sci. 42 (2008) 470-477. doi:10.1016/j.commatsci.2007.08.011

[16] G. L. Ji., G. Yang, L. Li, Q. Li, Modeling Constitutive Relationship of Cu-0.4 Mg Alloy During Hot Deformation, J. Mater. Eng. Perform. 23 (2014) 1770-1779. doi:10.1007/s11665-014-0912-0

[17] N. Haghdadi, A. Zarei-Hanzaki, H. R. Abedi, The flow behavior modeling of cast A356 aluminum alloy at elevated temperatures considering the effect of strain, Mater. Sci. Eng. A 535 (2012) 252-257. doi:10.1016/i.msea.2011.12.076

[18] H. Clemens, H. Kestler, Processing and Applications of Intermetallic $\gamma$-TiAl-Based Alloys, Adv. Eng. Mater. 2 (2000) 551-570. doi:10.1002/1527-2648(200009)2:9<551::aidadem551>3.0.co;2-u

[19] F. Appel, M. Oehring, R. Wagner, Novel design concepts for gamma-base titanium aluminide alloys, Intermetallics 8 (2000) 1283-1312. doi:10.1016/s0966-9795(00)00036-4

[20] F. Appel, U. Brossmann, U. Christoph, S. Eggert, P. Janschek, U. Lorenz, J. Müllauer, M. Oehring, J. D. H. Paul, Recent Progress in the Development of Gamma Titanium Aluminide Alloys, Adv. Eng. Mater. 2 (2000) 699-720. doi:10.1002/1527-2648(200011)2:113.0.CO;2-J
[21] G. L. Chen, X. J. Xu, Z. K. Teng, Y. L. Wang, J. $\mathrm{P}$. Lin, Microsegregation in high $\mathrm{Nb}$ containing TiAl alloy ingots beyond laboratory scale, Intermetallics 15 (2007) 625-631. doi:10.1016/i.intermet.2006.10.003

[22] F. Kong, Y. Chen, D. Zhang, S. Zhang, High temperature deformation behavior of Ti-46Al-2Cr- $4 \mathrm{Nb}-$ 0.2Y alloy, Mater. Sci. Eng. A 539 (2012) 107-114. doi:10.1016/j.msea.2012.01.066

[23] T. Sakai, Dynamic Recrystallization Microstructures under Hot Working Conditions, J. Mater. Process. Technol. 53 (1995) 349-361. doi:10.1016/0924-0136(95)01992-N

[24] L. Cheng, H. Chang, B. Tang, H. Kou, J. Li, Deformation and dynamic recrystallization behavior of a high $\mathrm{Nb}$ containing TiAl alloy, J. Alloy Compd. 552 (2013) 363-369. doi:10.1016/i.jallcom.2012.11.076

[25] H. Zhou, F. Kong, X. Wang, Y. Chen, Hot deformation behavior and microstructural evolution of asforged Ti-44Al-8Nb-(W,B,Y) alloy with nearly lamellar microstructure, Intermetallics $81 \quad 2017 \quad 62-72$. doi:10.1016/i.intermet.2017.02.026

[26] Z. Gabalcová, J. Lapin, Estimation of high temperature phase equilibria in directionally solidified intermetallic Ti-45.9Al-8Nb alloy, Kovove Mater. 45 (2007) 231-240.

[27] J. Zollinger, Z. Gabalcová, D. Daloz, J. Lapin, H. Combeau, Microsegregation induced microstructures in intermetallic Ti-46Al-8Nb alloy, Kovove Mater. 46 (2008) 291-296.

[28] N. Cui, F. Kong, X. Wang, Y. Chen, H. Zhou, Hot deformation behavior and dynamic recrystallization of a $\beta$-solidifying TiAl alloy, Mat. Sci. Eng. A 652 (2016) 231-238. doi:10.1016/j.msea.2015.11.097

[29] C. M. Sellars, W. J. Mctegart, On the mechanism of hot deformation, Acta Metall. 14 (1966) 1136-1138. doi:10.1016/0001-6160(66)90207-0 